\section{Tension pneumothorax mimicking giant emphysematous bullae}

A 65-year-old man was admitted with left thoracic pain and dyspnoea. One year before admission, he had undergone talc pleurodesis by thoracoscopy to manage a left recurrent pneumothorax due to tobacco-related emphysema. Chest x-ray (figure 1) and CT scan (figure 2A-C) showed clustered air pockets in between normal lung parenchyma. It was unclear whether the radiological image was due to unilateral giant emphysematous bullae or to clustered pneumothorax following talcage, with areas of lung detachment in between areas of lung adhesion to the parietal pleura. A shift of the heart to the right was visible. The marked unilateral nature of the abnormal air

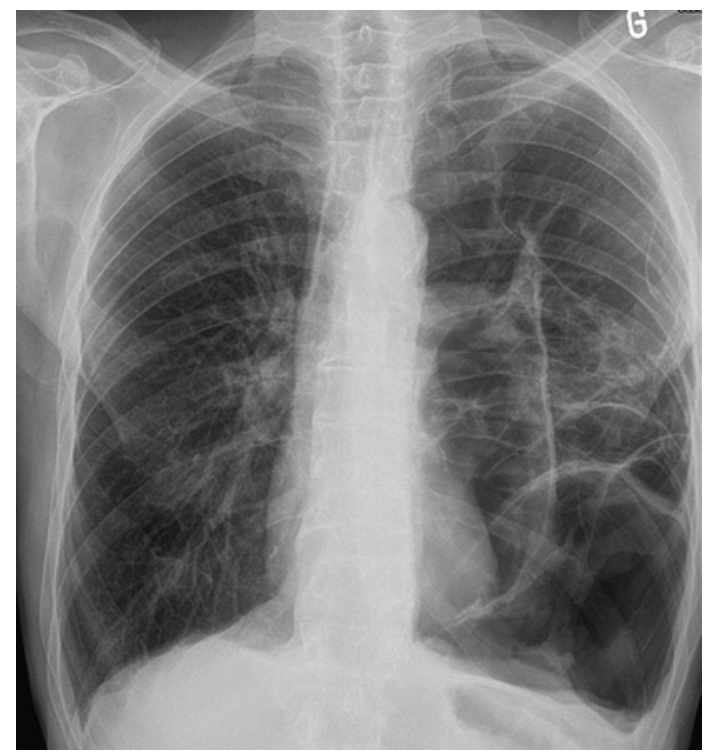

Figure 1 Chest x-ray showing clustered air pockets mimicking giant emphysematous bullae.

\section{Learning points}

- Tension pneumothorax after previous thoracic surgery can be misdiagnosed as giant emphysemateous bullae in the case of intense adhesion between lung and pleura.

- The unilateral nature of the air collection, the lack of vessels coursing through the wall of the bullae, the location within the major fissure and the absence of other smaller bullae in the controlateral lung are suggestive of a pneumothorax.

collection, the lack of vessels coursing through the wall of the bullae, the location within the major fissure and the absence of other smaller bullae in the left lung were suggestive of a pneumothorax. A left chest tube improved the patient's symptoms with re-expansion of the lung. The patient underwent pleurectomy by left thoracotomy. No emphysematous bullae were macroscopically visible, thus confirming the diagnosis of pneumothorax. Clustered tension pneumothorax is a rare condition that can be misdiagnosed as giant emphysematous bullae, especially after previous thoracic procedures.

\section{Michel Gonzalez, Thorsten Krueger, Hans-Beat Ris, Jean Y Perentes}

Department of Thoracic and Vascular Surgery, Centre Hospitalier Universitaire Vaudois, Lausanne, Switzerland

Correspondence to Dr Michel Gonzalez, Department of Thoracic and Vascular Surgery, University Hospital of Lausanne, Rue du Bugnon 46, Lausanne 1011, Switzerland; michel.gonzalez@chuv.ch

\section{Competing interest None.}

Patient consent Obtained.

Provenance and peer review Not commissioned; not externally peer reviewed.

Accepted 30 January 2010

Published Online First 7 June 2010

Thorax 2010;65:1028. doi:10.1136/thx.2009.129452 pneumothorax. Areas devoid of vascularisation coursing through the bullae and the absence of bullae in the contralateral lung are suggestive of pneumothorax. Areas of lung detachment are visible in between areas of lung adhesion to the parietal pleura. Tension pneumothorax is suggested by the mediastinal shift to the right as well as the image of a small heart. (B) Coronal view of the chest CT scan shows the communicating nature of the pneumothorax. Former areas of attachment to the parietal pleura are visible (thickening of the edges). (C) Sagittal view of the CT scan shows the communicating nature of the clustered pneumothorax in the major fissure. 